\title{
Electro encephalography screening of suspected epileptic patients in Erbil City
}

\begin{abstract}
Background and objective: Electroencephalography is an essential component in the evaluation of patients with epilepsy. Electroencephalography provides important information about background electroencephalography and epileptiform discharges and the interictal spike or sharp waves. This study aimed to differentiate between epileptic and non-epileptic patients through electroencephalography investigation and determine its relationship with certain socio-demographic and clinical characteristics.
\end{abstract}

Methods: In this cross-sectional study included 400 cases (205 males and 195 females) with a mean age \pm SD of $25 \pm 14$ years, referred to the private neurology clinic, Soran Medical Center between April 2013 and March 2017 for attacks of abnormal movements and or disturbed level of consciousness.

Results: Age-related prevalence of epilepsy showed a significantly higher prevalence $(P=0.001)$ of the disease among those who were 20 years and more. Epileptic patients showed significantly $(P=0.001)$ higher sharp slow waves and sharp waves, which were mainly dominated by parietal and occipital regions of the brain. Electroencephalography finding showed higher Beta rhythm followed by Alpha and Delta rhythms (73.5\%, 14.3\% and $9.0 \%$, respectively), Patients with epilepsy (generalized and focal) had shown best rhythm adoption in Beta rhythm (75.2\% and $70.2 \%$, respectively), followed by Alpha rhythm $(13.2 \%$ and $14.8 \%$, respectively). Focal to bilateral (secondary generalized) and generalized motor epilepsy were the most common diagnosis among the epileptic cases (45.4\% and $43.4 \%$, respectively). The overall sensitivity of electroencephalography was $67.8 \%$, and specificity was $63.5 \%$.

Conclusion: The electroencephalography showed good sensitivity and specificity in diagnosing suspected epileptic patients, with interesting higher sensitivity than specificity. Not only the abnormal discharges, but the background dominating activity and the best rhythm adoption can help in the diagnosis of epilepsy.

Keywords: Erbil; Epilepsy; EEG; Sensitivity; Specificity.

\section{Introduction}

Electroencephalography (EEG) is an essential component in the evaluation of epilepsy. The EEG provides important information about background EEG and epileptiform discharges and the interictal spike or sharp wave. These discharges may be either generalized or focal in distribution and help to classify whether a focal or generalized seizure disorder is present. $^{1,2}$ EEG can help identify seizures type and localization of epileptic focus. Also, some patterns of EEG are predictive of patients who can develop lateonset seizures, in addition, ${ }^{3}$ epilepsy is a condition of chronic, recurring seizures and its most disabling aspect is the unpredictability of when and where the next seizure will occur. Its etiology is complex and heterogeneous. Its prevalence varies in relation to ethnicity, geography, age, and sex. Seizure frequency, type, and duration are other important characteristics of epilepsy in a population. ${ }^{4}$ It has been estimated that approximately $17-30 \%$ of outpatients

${ }^{1}$ Department of Medicine, College of Medicine, Hawler Medical University, Erbil, I raq.

* Correspondence: mhummadi7@yahoo.com 
presented to comprehensive epilepsy centers for evaluation have psychogenic non-epileptic seizures (PNES). It is therefore important that epilepsy centers provide an evaluation process in order to differentiate epileptic seizures from other paroxysmal non-epileptic events. ${ }^{4}$ Epilepsy is affecting millions of patients worldwide, with a prevalence rate ranging from 16-51 per 100000 population in the developed countries' to 35-111 per $100 \quad 000$ population in the developing countries. ${ }^{6-8}$ Epilepsy starts in childhood in $60 \%$ of cases and most of the clinically significant aspects of the disease occur during childhood. $^{9}$ Most studies of epilepsy indicate that males are more frequently affected than females and generalized seizures to be more common than focal seizures. ${ }^{10}$ The wrong diagnosis of epilepsy is, unfortunately, common. Of patients diagnosed with epilepsy who are seen at epilepsy centers, $20 \%$ to $30 \%$ are found to have been misdiagnosed. This percentage is astonishingly consistent across centers, countries, and continents. ${ }^{11}$ In the majority of cases when first seen, the causative factors are not evident by history and clinical examination alone. Hence, a diagnostic tool like EEG is employed; normal EEG does not exclude the presence of epilepsy. ${ }^{12}$ Our country is a developing country, and clinical characteristics of epilepsy are not yet completely understood in Iraq and the Kurdistan region. Moreover, the scarce data on this important problem in our community provided the impetus to conduct this study. This study aimed to differentiate between epileptic and non-epileptic patients through EEG investigation and determine its relationship with certain socio -demographic and clinical characteristics. This study will provide baseline data for further researches in the area, which may lead to a better understanding of epilepsy features, and could provide better management and control of the disease.

\section{Methods}

This cross-sectional study included 400 cases referred to the private clinic in Soran Medical Center between April 2013 and March 2017 for attacks of abnormal movements and or disturbed level of consciousness aiming to differentiate between epileptic and non- epileptic patients. The study was conducted in Erbil governorate with a catchment population of around $1,750,000$ population. ${ }^{13}$ Soran Medical Center was established in 2008 in Erbil city, and includes different specialties. The center is equipped with 1.5 Tesla MRI machine, spiral CT scan and 20 electrodes advanced EEG machine from Xaimedicacompany. The neurology unit in the center is run by a consultant neurologist. Patients were informed about the study, and then informed consent was obtained from each patient. Their demographic characteristics, including age, sex, and history of epilepsy, were documented. The EEG study, including four sessions; background, activation reaction, rhythmic stimulation, and hyperventilation were recorded in dark and calm room. Each study lasts for about 30 minutes. Physiological electrical brain activity can be recorded within these rhythms, including alpha(8-12 Hz), beta(12-30 Hz), theta $(4-7 \mathrm{~Hz})$ and delta $(0.5-3 \mathrm{~Hz})$ rhythms. Classically, presence of sharp waves, sharp slow waves, spikes, and spike slow wave complex discharges focally or generalized are regarded to be abnormal. Other electroencephalographic findings were also documented including, background dominating activities, rhythmic stimulation rhythm adoption, the focus of the discharges, and finally the diagnosis. According to the protocol followed in the clinic, each patient should be assessed by an adult neurologist to obtain a detailed history and perform the neurological examinations, followed by an EEG. Epilepsy was suspected on history, clinical presentation and confirmed/categorized by EEG. Those who are diagnosed to be epileptic were thoroughly investigated by 
hematological workup and neuroimaging (computerized tomography C.T. or magnetic resonance imaging M.R.I. of the brain) according to indication for the cause of epilepsy. Patients of all ages and both sexes having a seizure-like presentation (attacks of recurrent reversible neurological disturbances) were included. All those patients with physical disorders not related to epilepsy like transient ischemic attacks (TIA), drop attacks, syncope, cardiac dysrhythmias, psychiatric disorders and those who refused to participate were excluded. Ethical approval was granted by the Research Ethics Committee of the College of Medicine, Hawler Medical University. Microsoft Excel was used for data processing, summarization. Tables and figures were used for presentation of the findings. Statistical analysis was performed by the statistical package for the social sciences (version 18). Chi-Square and Fischer's exact association tests were used to compare categorical variables. A $P$ value of $\leq 0.05$ was regarded as statistically significant.

\section{Results}

A total of 400 patients with suspected epilepsy were included in the current study. Their age ranged from two to 81 years with a mean age \pm SD of $25 \pm 14$ years. Among them, $76.0 \%$ had history of fits. Of those below 20 years, $85.5 \%$ had history of fits, while $68.2 \%$ of those aged 20 years or more had history of fits with significant statistical association between age groups of the participants and history of fits $(P=0.001)$. Among the males, $79.5 \%$ had history of fits, while only $72.3 \%$ of females had history of fits with a male to female ratio of $1.05: 1$ and no significant statistical difference $(P=0.102)$ in relation to the history of fits (Table 1 ).

Table1: Association between socio-demographic variables and history of fits.

\begin{tabular}{|c|c|c|c|c|}
\hline \multirow{2}{*}{ Variables } & \multicolumn{3}{|c|}{ History suggestive of fits } & \multirow{2}{*}{$P$ value } \\
\hline & $\begin{array}{c}\text { Yes } \\
\text { No. (\%) }\end{array}$ & $\begin{array}{c}\text { No } \\
\text { No. (\%) }\end{array}$ & $\begin{array}{c}\text { Total } \\
\text { No. (\%) }\end{array}$ & \\
\hline \multicolumn{5}{|c|}{ Age groups } \\
\hline$<20$ years & $154(85.5)$ & $26(14.5)$ & $180(100.0)$ & \multirow[b]{2}{*}{0.001} \\
\hline$\geq 20$ years & $150(68.2)$ & $70(31.8)$ & $220(100.0)$ & \\
\hline \multicolumn{5}{|l|}{ Gender } \\
\hline Male & $163(79.5)$ & $42(20.5)$ & $205(100.0)$ & \multirow{3}{*}{0.102} \\
\hline Female & $141(72.3)$ & $54(27.7)$ & $195(100.0)$ & \\
\hline Total & $304(76.0)$ & $96(24.0)$ & $400(100.0)$ & \\
\hline
\end{tabular}


Age-related prevalence of epilepsy showed statistically significant association between age groups of the patients and types of epilepsy $(P=0.001)$. Among those who were 20 years and more, generalized epilepsy was the most common type $(33.2 \%)$, and focal epilepsy was more prevalent $(41.6 \%)$ among those younger than 20 years. Gender-related prevalence of the disease had shown no significant difference $(P=0.403)$ in relation to the type of epilepsy. Focal epilepsy was more prevalent $(33.2 \%)$ in males, while generalized epilepsy was more prevalent $(32.3 \%)$ in females (Table 2). Regarding background dominating activities, the EEG findings showed that $46.3 \%$ of the dominating activities were from the parietal region of the brain, followed by occipital and temporal regions $(26.3 \%$ and $22.8 \%$, respectively), as shown in Figure 1.

Table 2: Association between socio-demographic characteristics of the patients and types of epilepsy

\begin{tabular}{lccccc}
\hline Variables & $\begin{array}{c}\text { Types of epilepsy } \\
\text { No. (\%) }\end{array}$ & $\begin{array}{c}\text { Generalized } \\
\text { No. (\%) }\end{array}$ & $\begin{array}{c}\text { Focal } \\
\text { No. (\%) }\end{array}$ & $\begin{array}{c}\text { Total } \\
\text { No. (\%) }\end{array}$ & P value \\
\hline $\begin{array}{l}\text { Age groups } \\
<20 \text { years }\end{array}$ & $57(31.7)$ & $48(26.7)$ & $75(41.6)$ & $180(100.0)$ & 0.001 \\
$\geq 20$ years & $101(45.9)$ & $73(33.2)$ & $46(20.9)$ & $220(100.0)$ & \\
$\begin{array}{l}\text { Gender } \\
\text { Male }\end{array}$ & $79(38.5)$ & $58(28.3)$ & $68(33.2)$ & $205(100.0)$ & 0.403 \\
Female & $79(40.5)$ & $63(32.3)$ & $53(27.2)$ & $195(100.0)$ & \\
Total & $158(39.5)$ & $\mathbf{1 2 1}(\mathbf{2 8 . 2 5})$ & $\mathbf{1 2 1 ( 2 8 . 2 5 )}$ & $\mathbf{4 0 0 ( 1 0 0 . 0 )}$ & \\
\hline
\end{tabular}

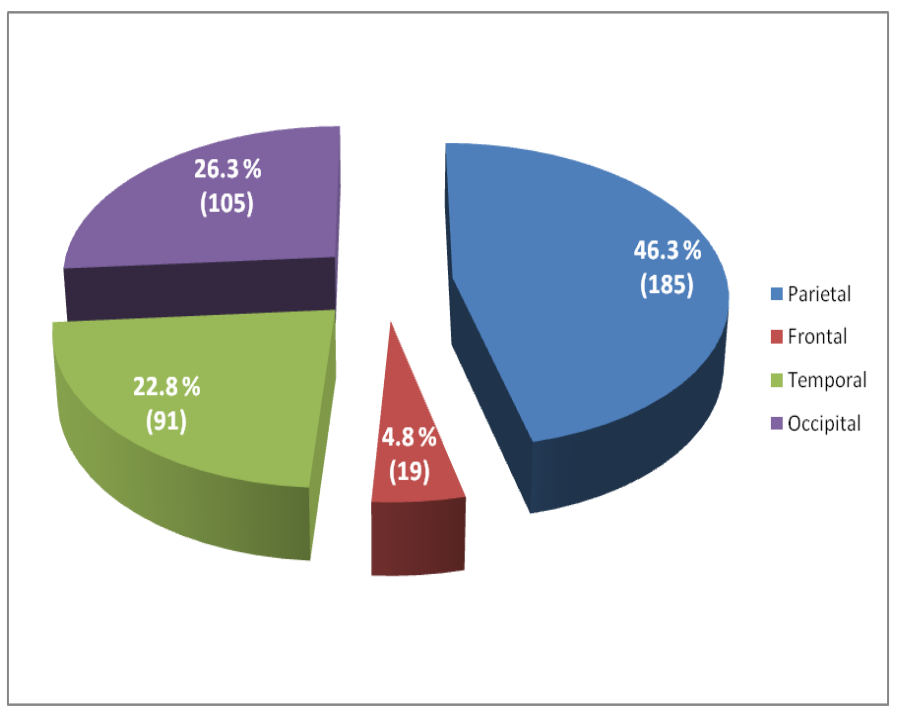

Figure 1: Background dominating activities by EEG finding. 
The dominating activities were mainly from parietal, temporal and occipital regions of the brain, and there was a significant statistical association ( $P=0.001$ ) between abnormal discharges and background dominating activities, where sharp slow waves and sharp waves were the most dominating abnormal discharges. Sharp slow waves were more dominant in parietal, temporal then occipital lobes $(47.0 \%, 32.9 \%$, and $16.8 \%$, respectively). However, sharp waves were more dominant in parietal, occipital, and temporal regions $(54.1 \%, 30.5 \%$, and $12.5 \%$, respectively). Epileptic patients (those with generalized epilepsy) had more dominating activities in the parietal and temporal regions (36.4\% and $33.1 \%$, respectively), and those with focal to bilateral epilepsy (secondary generalized) showed more dominating activities in the parietal and temporal regions $(59.5 \%$ and $24.8 \%$, respectively), with significant statistical association $(P=0.001)$ between types of epilepsy and background dominating activities (Table 3).

Table 3: Background dominating activities in relation to abnormal discharges, and focus of the discharges.

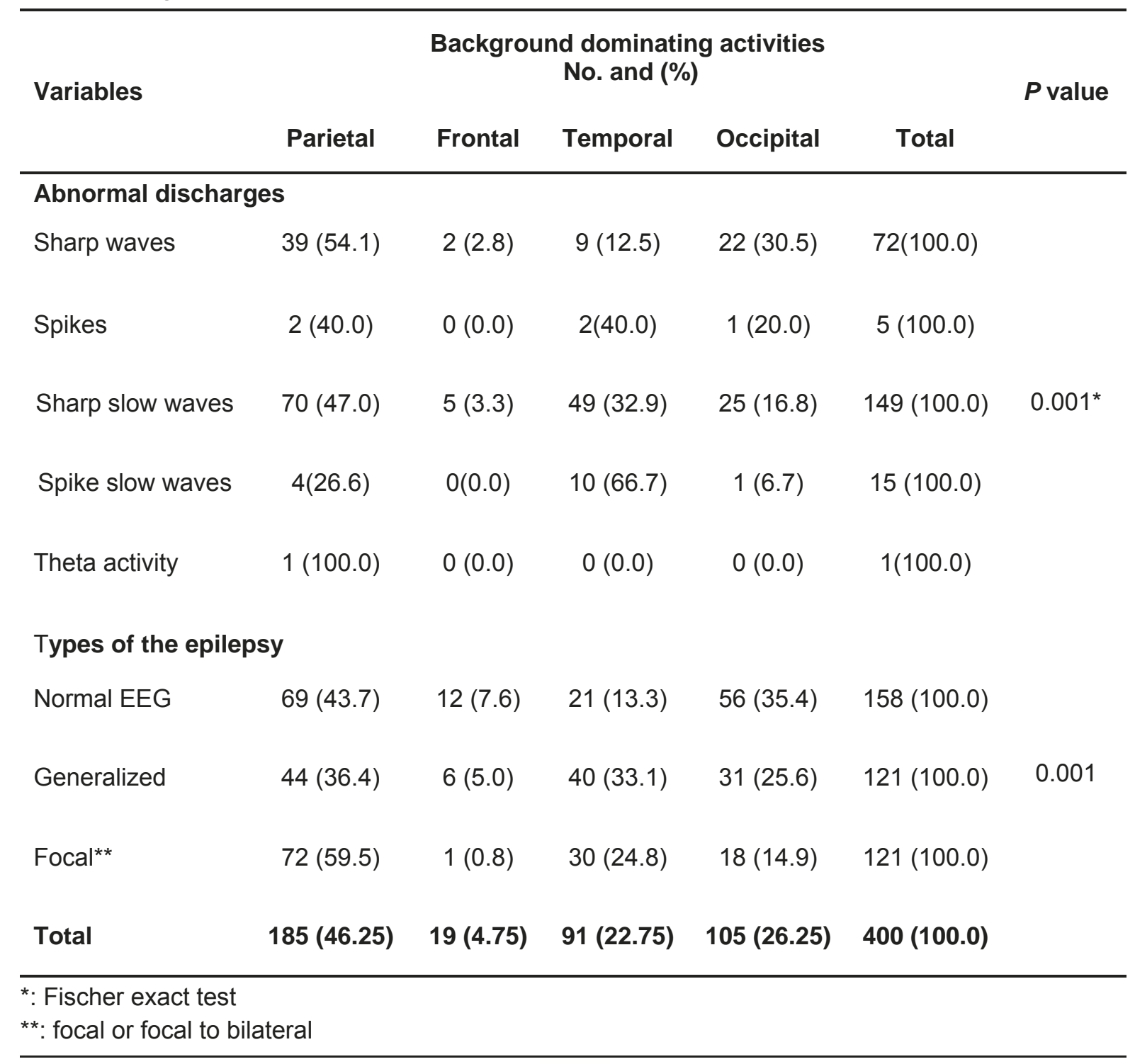


Comparing the best rhythm adoption in rhythmic stimulation part of the EEG to the affected brain lobes by EEG finding, showed higher Beta rhythm followed by Alpha and Delta rhythm (73.5\%, 14.3\%, and $9.0 \%$, respectively) as shown in Figure 2. The parietal region showed higher Beta rhythm followed by Alpha and Delta rhythm $(76.8 \%, 9.7 \%$ and $8.5 \%$, respectively). The same is true in both frontal and occipital regions, with no significant statistical difference $(P=0.190)$.
Beta rhythm stimulation was the most dominating one in relation to all the discharged waves followed by Alpha rhythm with no statistical difference $(P=0.855)$. Patients with epilepsy (generalized and focal) had shown best rhythm adoption in Beta rhythm (75.2\% and $70.2 \%$, respectively), followed by Alpha rhythm $(13.2 \%$ and $14.8 \%$, respectively), with no significant statistical difference $(P=0.958)$ as shown in Table 4.

Table 4: The best rhythm adoption in relation to affected lobe by EEG finding, abnormal discharges, and type of epilepsy.

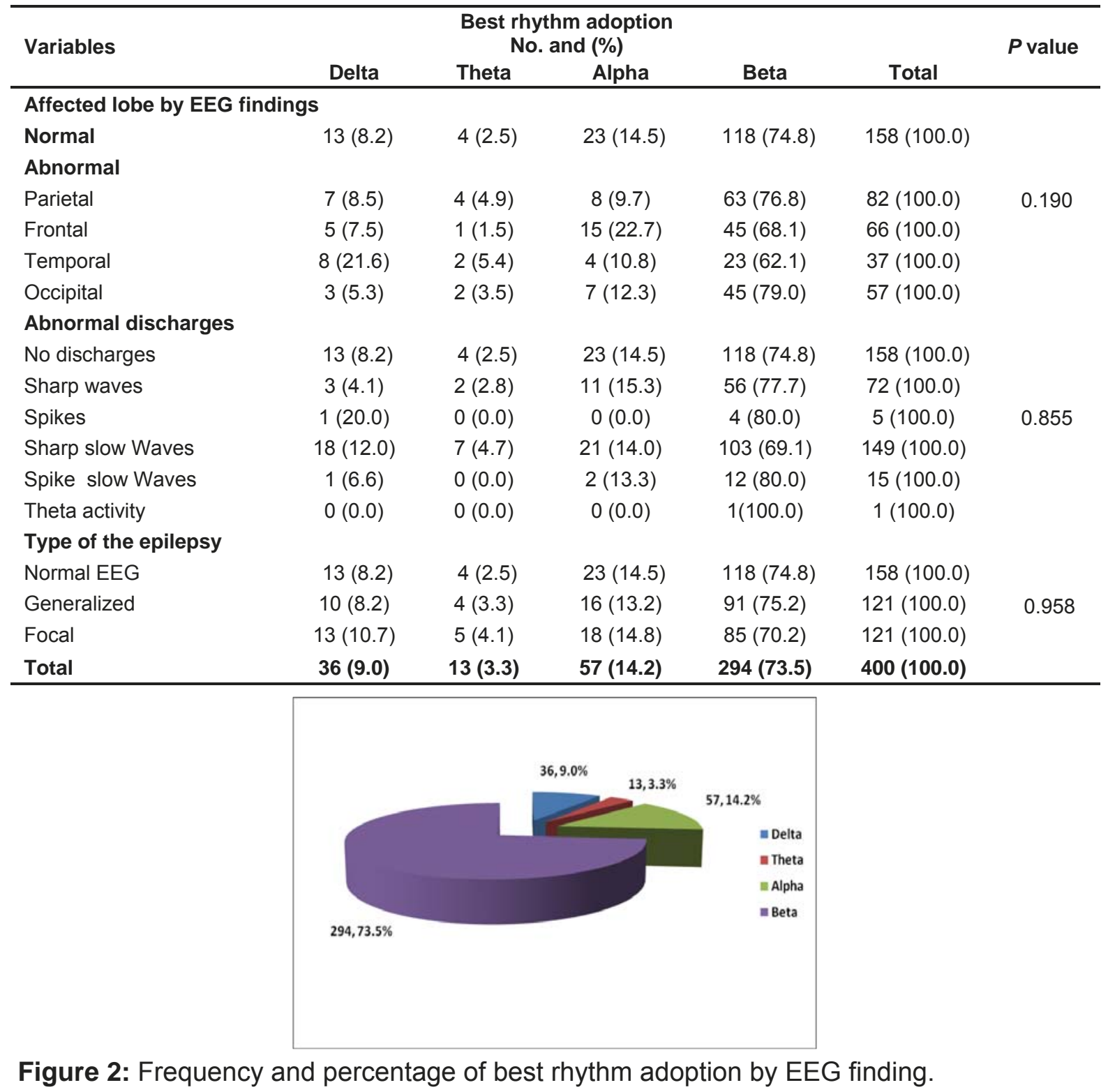


The final diagnosis of the patients by the EEG findings revealed that $158(39.5 \%)$ of the patients were normal compared to 242 $(60.5 \%)$ of abnormal cases (epileptics). Of all the patients, $15 \%$ had no history suggestive of fits, while $85 \%$ had history suggestive of fits, with a significant statistical association $(P=0.001)$. Focal to bilateral epilepsy and generalized epilepsy were the most common diagnosis among the epileptic patients $(45.5 \%$ and $43.3 \%$, respectively) and was more dominant among patients with a history suggestive of fits (Figure 3 ). There was a significant statistical difference $(P=0.001)$ in comparing the active brain lobes in EEG finding to history suggestive of fits. The parietal and frontal regions were the main focus of epilepsy with more focus of discharges $(76.0 \%)$ among those with history suggestive of fits, compared to $24.0 \%$ of those who had no history suggestive of fits (Table 5 ).

Table 5: Clinical characteristics of the study sample by EEG findings in relation to the history of fits.

\begin{tabular}{|c|c|c|c|c|}
\hline \multirow[b]{2}{*}{ Variables } & \multicolumn{3}{|c|}{ History suggestive of fits } & \multirow[b]{2}{*}{$P$ value } \\
\hline & $\begin{array}{c}\text { Yes } \\
\text { No. (\%) }\end{array}$ & $\begin{array}{c}\text { No } \\
\text { No. (\%) }\end{array}$ & $\begin{array}{c}\text { Total } \\
\text { No. (\%) }\end{array}$ & \\
\hline \multicolumn{5}{|l|}{ Diagnosis } \\
\hline Normal & $98(62.0)$ & $60(38.0)$ & $158(100.0)$ & \\
\hline \multicolumn{5}{|l|}{ Abnormal } \\
\hline Generalized & $95(90.5)$ & $10(9.5)$ & $105(100.0)$ & \multirow{7}{*}{$0.001^{*}$} \\
\hline Focal epilepsy & $11(84.6)$ & $2(15.4)$ & $13(100.0)$ & \\
\hline Focalto bilateral epilepsy (secondary generalized) & $87(79.0)$ & $23(21.0)$ & $110(100.0)$ & \\
\hline Focal with impaired awareness (temporal lobe epilepsy) & $5(83.3)$ & 1(16.7) & $6(100.0)$ & \\
\hline Generalized non motor (absence seizure) & $6(100.0)$ & $0(0.0)$ & $6(100.0)$ & \\
\hline Rolandic (focal) epilepsy & $2(100.0)$ & $0(0.0)$ & $2(100.0)$ & \\
\hline Subtotal & $206(85.0)$ & $36(15.0)$ & $242(100.0)$ & \\
\hline \multicolumn{5}{|l|}{ Focus of epilepsy on EEG finding } \\
\hline Normal & (62.0) 98 & $(38.0) 60$ & $158(100.0)$ & \\
\hline \multicolumn{5}{|l|}{ Abnormal } \\
\hline Parietal & $(85.3) 70$ & $12(14.2)$ & (100.0) 82 & \multirow{5}{*}{0.001} \\
\hline Frontal & $57(86.3)$ & $9(13.7)$ & $66(100.0)$ & \\
\hline Temporal & $31(83.8)$ & $(16.2) 6$ & $37(100.0)$ & \\
\hline Occipital & $48(84.2)$ & $9(15.8)$ & $57(100.0)$ & \\
\hline Total & $304(76.0)$ & $96(24.0)$ & $400(100.0)$ & \\
\hline
\end{tabular}

* Fischer exact test

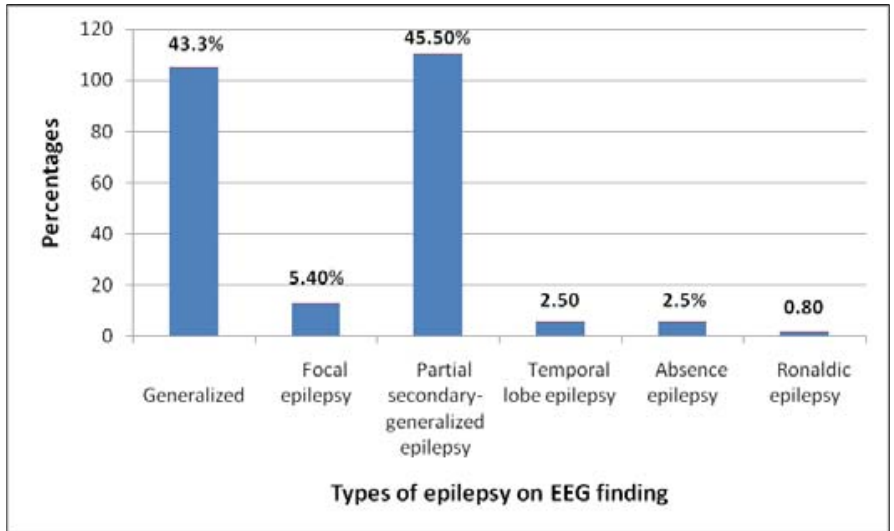

Figure 3: The final diagnosis of epileptic patients by EEG finding. 
The EEG was normal among 98 patients who were clinically suggestive of seizure and was abnormal in 36 patients who had a vague description of fainting attacks. The overall sensitivity of EEG was $67.8 \%(95 \%$ confidence interval (Cl) $62.19 \%$ to $72.99 \%$ ) and specificity was $63.5 \%(95 \% \mathrm{Cl} 52.03 \%$ to 72.18 ), as shown in Table 6.

\section{Discussion}

The profile of epilepsy varies across various cultures, ${ }^{14}$ and the frequency of reported EEG abnormalities in patients with seizures commonly differs between studies. The sensitivities of EEG range from 29 to $69 \%$. Even when EEGs are repeated in the same patient, the results are often not consistent. Differences in reported test characteristics could be related to variations in patient characteristics or to reader's threshold variations for interpreting tests as positive. ${ }^{15}$ Results of the study showed that age-related prevalence of epilepsy showed a significantly higher prevalence of the disease among those who were 20 years or above. Among them, generalized epilepsy was the most common type, and focal epilepsy was more prevalent among those aged less than 20 years. Focal epilepsy was more prevalent among males, followed by a higher prevalence of generalized epilepsy in females. Studies in Pakistan and Saudi Arabia revealed that generalized seizures were the most common seizure type. ${ }^{16,17}$ Another study in Egypt showed that focal seizures were the commonest type. ${ }^{18}$ As the age is increased, the EEGs findings showed more generalized epileptic potentials; this was in contrast to a study in India. ${ }^{19}$ These differences could be due to different patients characteristics from genetic factors, to other socio-demographic factors. Gender-related prevalence of the disease had shown no significant difference in relation to the type of epilepsy. A study in Bangladesh showed a higher incidence of the disease among younger age groups, with more prevalence among males, and for most incidence studies, sex-specific differences in incidence are not statistically significant. ${ }^{15}$ Another study in the USA revealed no significant statistical differences by age group and gender among the study participants. ${ }^{20}$ This could be due to greater outdoor activities and more exposure to risk factors, which might expose males to a higher risk of epilepsy than females. Regarding background dominating activities, the study showed that the main dominating activities were from the parietal region of the brain, followed by occipital and temporal regions; this is inconsistent with a study in Bangladesh, which showed that the most common site of origin of epileptiform discharge was temporal lobe $(28.3 \%){ }^{15}$ About two-thirds of the patients showed epileptic discharges, almost similar results were reported in an Indian study, where more than $70 \%$ of the patients had abnormal EEG findings. ${ }^{21}$ Among those with abnormal discharges showed significantly higher sharp slow waves and sharp waves, almost similar results were reported in another Indian study, where the sharp waves were the most predominant

Table 6: Sensitivity and specificity of EEG.

\begin{tabular}{|c|c|c|c|c|c|}
\hline \multirow{2}{*}{$\begin{array}{l}\text { Test } \\
\text { EEG }\end{array}$} & \multicolumn{2}{|c|}{ History suggestive of seizures } & \multirow{2}{*}{ Total } & \multirow{2}{*}{$\begin{array}{l}\text { Sensitivity } \\
(95 \% \mathrm{Cl})\end{array}$} & \multirow{2}{*}{$\begin{array}{l}\text { Specificity } \\
(95 \% \mathrm{Cl})\end{array}$} \\
\hline & Yes & No & & & \\
\hline Abnormal & $206(85.0 \%)$ & $36(15.0 \%)$ & 242 & & \\
\hline Normal & $98(62.0 \%)$ & $60(38.0 \%)$ & 158 & $\begin{array}{c}67.8 \\
(62.19-72.99)\end{array}$ & $\begin{array}{c}62.5 \\
(52.03-72.18)\end{array}$ \\
\hline Total & 304 & 96 & 400 & & \\
\hline
\end{tabular}


waveforms. $^{22}$ Also, similar results were reported in a study in Pakistan showed that the commonest epileptiform discharges were focal sharp and slow waves seen in $9.8 \%$ of patients. ${ }^{3}$ This could be attributed to the pattern of the disease and good sensitivity and specificity of the EEG. Comparing the best rhythm adoption to the affected brain lobes by EEG finding, showed higher Beta rhythm followed by Alpha and Delta and one-fifth of all the rhythmic stimulation was from the parietal region. In contrast, a study in Japan revealed a significant difference only in the delta frequency power bands in the frontal region of the brain. ${ }^{23}$ Another study in Norway showed higher Alpha activity in parieto-occipital and temporal regions of the brain; ${ }^{24}$ this could be due to the background etiology of the disease and some other clinical features of the patients. The final diagnosis of the patients obtained by the EEG revealed that $39.5 \%$ of the patients were normal compared to $60.5 \%$ of abnormal cases (epileptics). Focal to bilateral epilepsy and generalized epilepsy were the most common diagnosis among the epileptic cases, and the parietal and frontal regions of the brain were the main focus of epilepsy. A study in Bangladesh revealed that among the abnormal EEG findings (59\%), the generalized epileptiform discharge was found in $29 \%$, whereas focal and secondary generalized (focal to bilateral) discharge was found in $30 \%$ of the cases. The most common site of origin of epileptiform discharge was temporal lobe $(28.3 \%) .{ }^{15}$ This could be due to the background etiology of the disease, patients' clinical features, and sensitivity and specificity of the EEG. The overall sensitivity of EEG was $67.8 \%(95 \% \mathrm{Cl}$ $62.19 \%-72.99 \%$ ), and the specificity was $63.5 \% \quad(95 \% \mathrm{Cl}$ 52.03\%-72.18); almost similar results were reported in other studies in Bangladesh, Pakistan and Netherland. ${ }^{15,16,25}$ The current study is the first study in the Kurdistan region and Iraq addressing sensitivity and specificity of
EEG among suspected patients with epilepsy. This study has a number of limitations. Some demographic and social characteristics of the patients were not addressed in addition to the possible underlying causes and family history of the disease that could contribute more to epileptiform discharges.

\section{Conclusion}

This study had concluded that the EEG showed good sensitivity and specificity in diagnosing suspected epileptic patients, with interesting higher sensitivity than specificity, which may indicate that EEG still remains the best investigation tool in diagnosing patients with a suggestive history of fits.

\section{Competing interests}

The author declares no competing interests.

\section{References}

1. Sheth RJ, Benbadis SR. EEG in Common Epilepsy Syndromes; 2016. (Accessed July 23, 2017, at http://emedicine.medscape.com/ article/1138154-overview).

2. Zubcevic S, Milos M, Catibusic F, Uzicanin S, Krdzalic B. Interictal Electroencephalography (EEG) findings in children with epilepsy and bilateral brain lesions on Magnetic Resonance Imaging (MRI). Acta Inform Med 2015; 23:343-6.

3. Siddiqui M, Yaqoob U, Bano A, Malik A, Khan FS, Siddiqui K. EEG findings in post stroke seizures: an observational study. Pak J Med Sci 2008; 24:386-9.

4. Pal SK, Sharma K, Prabhakar S, Pathak A. Neuroepidemiology of epilepsy in Northwest India. Annal Neurosci 2010; 17:160-6.

5. Turner K, Piazzini A, Chiesa V, Barbieri V, Vignoli A, Gardella E, et al. Patients with epilepsy and patients with psychogenic non-epileptic seizures: Video- EEG, clinical and neuropsychological evaluation. Seizure 2011; 20:706-10.

6. Al-Kattan M, Afifi L, Shamloul R, Mostafa E. Assessment of precipitating factors of breakthrough seizures in epileptic patients. Egypt J Neurol Psychiat Neurosurg 2015; 52:165-71.

7. Yazdi MR, Farsi Baf MM, Afsari A, Alipour A, Khorashadizadeh M, Ghiassi PK, et al. Clinical features of epilepsy at 2 referral hospitals in Northern Iran. Neurosciences 2015; 20:243-7.

8. Camfield P1, Camfield C. Incidence, prevalence and etiology of seizures and epilepsy in children. Epileptic Disord 2015; 17:117-23. 
9. Hamdy NA. Prevalence of Epilepsy in primary school children in El- Minia City. Egypt. Egypt J Neurol Psychiat Neurosurg 2009; 46(1):33-9.

10. Hamdy NA, Alamgir JA, Mohammad EE, Khedr MH, Fazili S. Profile of epilepsy in a regional hospital in Al Qassim, Saudi Arabia. Int J Health Sci 2014; 8:247-55.

11. Benbadis $\mathrm{S}$. The differential diagnosis of epilepsy: A critical review. Epilepsy Behav 2009; 15:15-21.

12. Deme S. A study of correlation of CT scan brain and EEG in epilepsy. Int Arch Integ Med 2016; $3: 55-60$.

13. Iraq, the population of the provinces and province capitals of the Republic of Iraq. (Accessed July 25, 2017, at http://www.citypopulation.de/ Iraq.html).

14. Pal SK, Sharma K, Prabhakar S, Pathak A. Neuro-epidemiology of Epilepsy in Northwest India. Ann Neurosci 2010; 17:160-6.

15. Chowdhury $\mathrm{AH}$, Chowdhury RN, Khan SU, Ghose SK, Wazib A, Alam I, et al. Sensitivity and specificity of Electroencephalography (EEG) among patients referred to an electrophysiology Lab. In Bangladesh. J Dhaka Med Coll 2014; 23(2):215-22.

16. Khatri IA, lannaccone ST, Ilyas MS, Abdullah M, Saleem S. Epidemiology of epilepsy in Pakistan: Review of literature. J Pak Med Assoc 2003; 53:594-7.

17. Al- Sulaiman AA, Ismail HM. Clinical pattern of newly-diagnosed seizures in Saudi Arabia: a prospective study of 263 children. Childs Nerv Syst 1999; 15:468-71.

18. Hashem S, Al-Kattan M, Ibrahim SY, Shalaby NM, Shamloul RM, Farrag M. Epilepsy prevalence in Al-Manial Island, Egypt. A door-todoor survey. Epilepsy Research 2015; 117:1337.

19. Deme S. A study of correlation of CT scan brain and EEG in epilepsy. Int Arch Integ Med 2016; 3:55-61.

20. Hawley SR, Ablah E, Hesdorffer D, Pellock JM, Lindeman DP, Paschal AM, et al. Prevalence of pediatric epilepsy in low-income rural Midwestern counties. Epilepsy Behav 2015; 53:190-6.

21. Baheti R, Gupta BD, Baheti R. A Study of CT and $E E G$ findings in patients with generalized or partial seizures in Western Rajasthan. Ind Acad Clin Medi 2003; 4:25-9.

22. Bhuyan R, Jahan W, Upadhyaya N. Interictal wave pattern study in EEG of epilepsy patients. Int J Res Med Sci 2017; 5:3378-84.

23. Oguri M, Saito Y, Fukuda C, Kishi K, Yokoyama A, Lee S. Distinguishing acute Encephalopathy with biphasic seizures and late reduced diffusion from prolonged febrile seizures by acute phase EEG spectrum analysis. Yonago Actamedica 2016; 59:1-14.
24. Bjørk $M H$, Sand $T$, Bråthen $G$, Linaker $O M$, Morken $G$, Brigt $M$, et al. Quantitative EEG findings in patients with acute, brief depression combined with other fluctuating psychiatric symptoms: a controlled study from an acute psychiatric department. BMC Psychiatry 2008; 8:89:1-8.

25. Geut I, Weenink S, Knottnerus IL. Detecting interictal discharges in first seizure patients: ambulatory EEG or EEG after sleep deprivation. Seizure 2017; 51:52-4. 